\title{
ANALISIS PERFORMANCE CASUAL WORKER WAREHOUSE DI PERUM BULOG SUB DIVRE SURAKARTA
}

\author{
Samsoel Bahry, Rochmi Widayanti , Ratna Damayanti \\ Universitas Islam Batik Surakarta \\ Email: Samsoelbarbel@gmail.com
}

\begin{abstract}
Casual workers, better known as freelance workers, are human resources that have special specifications using body power possessed by Public Corporation of BULOG as a loading and unloading force of commodity goods, as well as processing units of food commodities in warehouses. This research is included in a quantitative descriptive study with a population of casual worker warehouses totaling 230 people in this study taken $50 \%$ as a source of data as many as 115 people. The data used in this study is primary data with a questionnaire method for respondents. Data is processed using IBM SPSS Statistics 17 multiple linear test. Based on the results of multiple linear regression tests, it shows that Job Training, Work Environment and Work Compensation partially influence the performance of casual worker warehouses at the Sub-Division of Regional Division of Surakarta. While the work discipline partially does not affect the performance of casual worker warehouses at the Sub Division of Surakarta Regional Office of Logistics, which is indicated by the significance of job training $0.002<0.05$, work environment 0,000<0.05, work discipline 0.454>0.05, work compensation $0,000<0,05$. Referring to the formulation of the problem, it can be concluded that work training, work environment and compensation have an effect, while work discipline does not affect the performance of casual worker warehouses at the Sub-Division of Regional Division of Surakarta. Optimal employee performance causes the company to achieve the company's vision and mission well
\end{abstract}

Keywords: Job training, work environment, work discipline, and work compensation, performance, employees.

\section{PENDAHULUAN}

Perkembangan zaman yang semakin modern di era milineal ini dituntut adanya sumber daya manusia (SDM) yang berkualitas tinggi. Sumber daya manusia merupakan aset terpenting perusahaan karena berperan sebagai subyek pelaksana kebijakan dan kegiatan operasional perusahaan. . Sumber daya yang dimiliki oleh perusahaan seperti modal, metode dan mesin tidak bisa memberikan hasil yang optimal apabila tidak didukung oleh sumber daya manusia yang mempunyai kinerja yang optimal (Hartatik,2014). Menurut Iswahyudar, Halin, Roswaty (2017) untuk mencapai kinerja yang memuaskan diperlukan kemampuan profesional untuk mencapainya harus melalui beberapa tahapan atau kondisi. Penelitian ini termasuk dalam penelitian Deskriptif kuantitatif dengan populasi casual worker warehouse sejumlah 230 orang dalam penelitian ini diambil 50\% sebagai sumber data yaitu sebanyak 115 orang. Data yang digunakan dalam penelitian ini merupakan data primer dengan metode penyebaran angket pada responden. Data diolah dengan menggunakan IBM SPSS Statistic 17 uji linier berganda. 


\section{KAJIAN TEORI}

\section{Pelatihan Kerja}

Pelatihan dan pengembangan sumber daya manusia merupakan hal yang sangat penting bagi karyawan untuk lebih menguasai dan bekerja lebih baik terhadap pekerjaan yang diemban. Mangkunegara (2010) mengatakan pelatihan merupakan suatu proses pendidikan jangka pendek yang mempergunakan prosedur sistematis dan terorganisir di mana pegawai non managerial mempelajari pengetahuan dan keterampilan teknis dalam tujuan terbatas". Kemudian Samsudin (2009) menyatakan bahwa pelatihan yaitu usaha untuk memperbaiki penguasaan berbagai keterampilan kerja dalam waktu yang relatif singkat (pendek).

Pelatihan menurut Dessler (2009) adalah "proses mengajarkan karyawan baru atau yang ada sekarang, ketrampilan dasar yang mereka butuhkan untuk menjalankan pekerjaan mereka". Pelatihan merupakan salah satu usaha dalam meningkatkan mutu sumber daya manusia dalam dunia kerja. karyawan, baik yang baru ataupun yang sudah bekerja perlu mengikuti pelatihan karena adanya tuntutan pekerjaan yang dapat berubah akibat perubahan lingkungan kerja, strategi, dan lain sebagainya.

\section{Lingkungan Kerja}

Lingkungan kerja merupakan segala sesuatu yang ada disekitar para pekerja yang dapat mempengaruhi dirinya dalam menjalankan tugas -tugas yang dibebankan (Hughes ,2007). Sependapat dengan Hughes (2007), menurut Al-Anzi (2009) lingkungan kerja fisik dalam suatu perusahaan merupakan suatu kondisi pekerjaan untuk memberikan suasana dan situasi kerja karyawan yang nyaman dalam pencapaian tujuan yang diinginkan oleh suatu perusahaan. Kondisi kerja yang buruk berpotensi menjadi penyebab karyawan mudah jatuh sakit, mudah stres, sulit berkonsentrasi dan menurunnya produktivitas kerja. Jika ruangan kerja tidak nyaman, panas, sirkulasi udara kurang memadai, ruangan kerja terlalu padat, lingkungan kerja kurang bersih, berisik, tentu besar pengaruhnya pada kenyamanan kerja.

\section{Disiplin Kerja}

Menurut Setiyawan dan Waridin (2006) disiplin kerja merupakan keadaan ideal dalam mendukung pelaksanaan tugas sesuai aturan dalam rangka mendukung optimalisasi kerja. Salah satu syarat agar disiplin dapat ditumbuhkan dalam lingkungan kerja ialah, adanya pembagian kerja yang tuntas sampai kepada pegawai atau petugas yang paling bawah, sehingga setiap orang tahu dengan sadar apa tugasnya, bagaimana melakukannya, kapan pekerjaan dimulai dan selesai, seperti apa hasil kerja yang disyaratkan, dan kepada siapa mempertanggung jawabkan hasil pekerjaan itu (Setiyawan dan Waridin, 2006). Untuk itu disiplin harus ditumbuh kembangkan agar tumbuh pula ketertiban dan efisiensi. Tanpa adanya disiplin yang baik, jangan harap akan dapat diwujudkan adanya sosok pemimpin atau karyawan ideal sebagaimana yang diharapkan oleh masyarakat dan perusahaan. Menurut Setiyawan dan Waridin (2006), serta Aritonang (2005) disiplin kerja karyawan bagian dari faktor kinerja.

\section{Kompensasi Kerja}

Dessler (2009), menjelaskan kompensasi karyawan merupakan semua imbalan atau pembayaran yang diterima oleh karyawan dari pekerjaan yang telah dilakukan karyawan tersebut. Pemberian sistem kompensasi yang efektif dapat membatu perusahaan untuk mempertahankan karyawan dengan kinerja baik karena manajemen sumber daya manusia sangat penting bagi perusahaan.

Di samping itu kompensasi yang diterima karyawan mempengaruhi kinerja yang akan dihasilkan. Jadi secara umum dapat dikatakan bahwa kompensasi merupakan imbalan yang diberikan oleh perusahaan sebagai balas jasa kepada karyawan atas kinerja yang telah dihasilkan untuk perusahaan tersebut.

\section{HASIL DAN PEMBAHASAN}

Berdasarkan hasil uji F menunjukkan bahwa pelatihan kerja, lingkungan kerja, disiplin kerja, dan kompensasi secara simultan atau bersama-sama berpengaruh secara signifikan antara pelatihan kerja, 
lingkungan kerja, disiplin kerja, dan kompensasi secara simultan terhadap kinerja casual worker warehouse di Perum BULOG Sub Divre Surakarta. Hal ini didasarkan pada hasil penelitian yang dapat dilihat dari Fhitung sebesar 12.545. Secara garis besar, pengaruh pelatihan kerja, lingkungan kerja, disiplin kerja, dan kompensasi berpengaruh dalam kinerja casual worker warehouse di Perum BULOG Sub Divre Surakarta.

Berdasarkan hasil analisis uji t diperoleh hasil bahwa pada pelatihan kerja, nilai signifikansi thitung $0,002<0,05$. Dapat disimpulkan bahwa ada pengaruh yang signifikan pelatihan kerja terhadap kinerja casual worker warehouse di Perum BULOG Sub Divre Surakarta. Pada lingkungan kerja, nilai signifikansi thitung $0,000<0,05$. Maka ada pengaruh yang signifikan lingkungan kerja terhadap kinerja casual worker warehouse di Perum BULOG Sub Divre Surakarta. Pada disiplin kerja, nilai signifikansi thitung 0,454 > 0,05. Maka tidak ada pengaruh yang signifikan dari disiplin kerja terhadap kinerja casual worker warehouse di Perum BULOG Sub Divre Surakarta. Pada kompensasi, nilai signifikansi thitung $0,000<0,05$. Maka ada pengaruh yang signifikan kompensasi terhadap kinerja casual worker warehouse di Perum BULOG Sub Divre Surakarta.

Berdasarkan hasil analisis uji t diperoleh hasil bahwa pelatihan kerja secara parsial berpengaruh signifikan terhadap kinerja casual worker warehouse di Perum BULOG Sub Divre Surakarta. Hal ini didasarkan pada hasil thitung yaitu sebesar 3,155. Artinya apabila pola pelatihan kerja yang ada semakin tinggi, maka kinerja casual worker warehouse di Perum BULOG Sub Divre Surakarta akan meningkat. Kenyataan pentingnya pelatihan kerja yang diadakan oleh perusahaan dalam mempengaruhi sikap dan perilaku karyawan. Jika pelatihan kerja bisa diperbaik, diharapkan akan lebih meningkatkan pengaruh positif terhadap kinerja casual worker warehouse di Perum BULOG Sub Divre Surakarta karena dapat memberikan motivasi dan wawasan baru pada karyawan.

Pelatihan kerja terbukti menjadi faktor yang berpengaruh terhadap kinerja casual worker warehouse di Perum BULOG Sub Divre Surakarta. Berdasarkan hasil analisis uji t diperoleh hasil bahwa lingkungan kerja secara parsial berpengaruh signifikan terhadap kinerja casual worker warehouse di Perum BULOG Sub Divre Surakarta. Hal ini didasarkan pada hasil thitung yaitu sebesar 4,035. Artinya apabila pola lingkungan kerja yang ada semakin tinggi, maka kinerja casual worker warehouse di Perum BULOG Sub Divre Surakarta akan meningkat. Kenyataan pengaruh lingkungan kerja yang terdapat di lingkungan perusahaan dalam mempengaruhi sikap dan perilaku karyawan. Lingkungan kerja yang lebih nyaman diharapkan dapat meningkatkan pengaruh positif terhadap kinerja casual worker warehouse di Perum BULOG Sub Divre Surakarta, karena dapat memberikan atmosfer positif pada karyawan.

Lingkungan kerja terbukti menjadi faktor yang mempengaruhi kinerja casual worker warehouse di Perum BULOG Sub Divre Surakarta. Berdasarkan hasil analisis uji t diperoleh hasil bahwa disiplin kerja secara parsial tidak berpengaruh signifikan terhadap kinerja casual worker warehouse di Perum BULOG Sub Divre Surakarta. Hal ini didasarkan pada hasil thitung 0,752. Kenyataan pentingnya aturan kerja yang diterapkan di lingkungan perusahaan terbukti belum mempengaruhi kedisiplinan pekerja. Pembagian tugas atau tupoksi dari tiap pekerja menjadi perhatian.

Dalam penelitian ini disiplin kerja terbukti tidak menjadi faktor yang berpengaruh pada kinerja casual worker warehouse di Perum BULOG Sub Divre Surakarta. Berdasarkan hasil analisis uji t diperoleh hasil bahwa pemberian kompensasi secara parsial berpengaruh signifikan terhadap kinerja casual worker warehouse di Perum BULOG Sub Divre Surakarta. Hal ini didasarkan pada hasil thitung yaitu sebesar 4,002. Artinya apabila pola pemberian kompensasi yang ada semakin tinggi, maka kinerja casual worker warehouse di Perum BULOG Sub Divre Surakarta akan meningkat, pemberian kompensasi yang merata menjadi faktor semangat karyawan untuk menjadi pekerja yang teladan. Adanya pemberian kompensasi yang tepat maka prestasi kerja akan meningkat karena setiap karyawan memiliki motif tertentu seperti pemenuhan kebutuhan fisik maupun psikologis pada saat mereka bekerja untuk perusahaan.

Nilai Adjusted R Square sebesar 0,288, hal ini menunjukkan bahwa variabel pelatihan kerja, lingkungan kerja, disiplin kerja, dan kompensasi mampu menjelaskan sebesar 28,8\% terhadap kinerja casual worker warehouse di Perum BULOG Sub Divre Surakarta. Sehingga masih terdapat pengaruh sebesar 71,2\% oleh variable lain seperti motivasi, kepemimpinan, komunikasi, team work, kepuasan kerja, pengetahuan dan lain-lain. 


\section{KESIMPULAN}

Berdasarkan hasil analisis data yang telah diuraikan pada hasil dan penjelasan, penulis dapat memberikan kesimpulan bahwa ada pengaruh yang simultan dan signifikan terhadap variabel pelatihan kerja, lingkungan kerja, disiplin kerja, dan kompensasi, pada kinerja casual worker warehouse di Perum BULOG Sub Divre Surakarta. Secara parsial pelatihan kerja berpengaruh signifikan terhadap kinerja casual worker di Perum BULOG Sub Divre Surakarta. Lingkungan kerja berpengaruh signifikan secara parsial terhadap casual worker warehouse di Perum BULOG Sub Divre Surakarta. Disiplin kerja tidak berpengaruh signifikan secara parsial terhadap casual worker warehouse di Perum BULOG Sub Divre Surakarta. Kompensasi berpengaruh positif dan signifikan secara parsial terhadap kinerja casual worker warehouse di Perum BULOG Sub Divre Surakarta.

\section{UCAPAN TERIMA KASIH}

Terimakasih saya haturkan kepada dewan redaksi Jurnal Edunomika yang telah memberikan kesempatan, sehingga tulisan saya bisa diterbitkan / dipublikasikan.

\section{DAFTAR PUSAKA}

Arifin, M. (n.d.). Pengaruh Kompensasi Dan Kepuasan Kerja Terhadap Kinerja (Studi Terhadap Fakultas Keguruan Dan Ilmu Pendidikan Universitas Muhammadiyah Sumatera Utara). 2017.

Aritonang, K. (2005). Kompensasi Kerja, Disiplin Kerja Guru dan Kinerja Guru SMP Kristen BPK PENABUR Jakarta. Guru SMP Kristen 1 BPK PENABUR Jakarta. . Jurnal Pendidikan Penabur No.4 Th.IV.

Bahri, S., \& Zamzam, F. (2015). Model Penelitian Kuantitatif Berbasis SEM-Amos. Yogyakarta: Deepulish.

Dessler, G. (2009). Manajemen SDM buku 1. Jakarta: Indeks.

Ghozali, I. (2013). Aplikasi Analisis Multivariate dengan Program SPSS Edisi Ketujuh. Semarang: Badan Penerbit Universitas Diponegoro.

Hartatik, I. P. (2014). Buku Praktis Mengembangkan SDM. Yogyakarta: Laksana.

Hasibuan, M. (2012). Manajemen Sumber DAya Manusia. Jakarta: PT Bumi Aksara.

Mangkunegara, A. P. (2010). Manajemen Sumber Daya ManusiaPerusahaan. Bandung: Remaja Rosdakarya.

Narmodo, H. (2011). Pengaruh Motivasi, Disiplin Kerja Terhadap Kinerja Pegawai padaBadan Kepegawaian Daerah Kabupaten Pasuruan. Vol 3 No 1.

Samsudin, S. (2010). Manajemen Sumber Daya Manusia. Bandung: CV Pustaka Setia.

Setiyawan, B., \& Waridin. (2006). Pengaruh Disiplin Kerja Karyawan dan Budaya Organisasi Terhadap Kinerja di Divisi Radiologi RSUP Dokter Kariadi. Semarang. JRBI, Hal: 181198. 
Subkhi, A., \& Jauhar, M. (2012). Pengantar Teori \& Perilaku Organisasi. Jakarta: Prestasi Pustaka.

Sugiyono. (2010). Metode Penelitian Pendidikan Pendekatan Kuantitatif, kualitatif, dan R\&D. Bandung: Alfabeta.

Sugiyono. (2013). Metode Penelitian Manajemen. Bandung: Alfabeta.

Yani, M. D., \& Dwiyanti, E. (2016). Hubungan Kompensasi Finansial Dan Stres Kerja Dengan Kinerja Karyawan PT DOK dan Perkapalan Surabaya (Persero). The Indonesian Journal of Occupational Safety and Health, Vol. 5, No. 2, 163-172. 